\begin{tabular}{|c|c|}
\hline Title & Supramolecular Conformational Control of A liphatic Oligoketones by Rotaxane Formation \\
\hline Author(s) & Manabe, Y umehiro; Wada, Keisuke; Baba, Y udai; Y oneda, Tomoki; Ogoshi, Tomoki; Inokuma, Y asuhide \\
\hline Citation & $\begin{array}{l}\text { Organic letters, 22(8), 3224.3228 } \\
\text { https://doi.org/10.1021/acs.orglett.0c01010 }\end{array}$ \\
\hline Issue Date & $2020-04-17$ \\
\hline Doc URL & http:/hdl. handle.net/2115/81007 \\
\hline Rights & $\begin{array}{l}\text { This document is the A ccepted Manuscript version of a Published Work that appeared in final form in Organic Letters, } \\
\text { copyright c A merican Chemical Society after peer review and technical editing by the publisher. To access the final } \\
\text { edited and published work see https:/pubs.acs.org/doi } 10.1021 / \text { acs.orglett.Oc01010. }\end{array}$ \\
\hline Type & article (author version) \\
\hline File Information & manuscript_revised (Org. Lett.).pdf \\
\hline
\end{tabular}

Instructions for use 


\title{
Supramolecular Conformational Control of Aliphatic Oligoketones by Rotaxane Formation
}

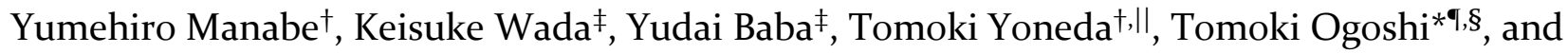 \\ Yasuhide Inokuma*t, II \\ †Division of Applied Chemistry, Faculty of Engineering, Hokkaido University, Kita 13, Nishi 8, Kita-ku, Sapporo, \\ Hokkaido o6o-8628, Japan \\ ${ }^{\ddagger}$ Graduate School of Natural Science and Technology, Kanazawa University, Kakuma-machi, Kanazawa, 920-1192, \\ Japan \\ 'Department of Synthetic Chemistry and Biological Chemistry, Graduate School of Engineering, Kyoto University, \\ Katsura, Nishikyo-ku, Kyoto 615-8510, Japan \\ §WPI Nano Life Science Institute, Kanazawa University, Kakuma-machi, Kanazawa 920-1192, Japan \\ "Institute for Chemical Reaction Design and Discovery (WPI-ICReDD), Hokkaido University, Kita 21, Nishi 10, Kita- \\ ku, Sapporo, Hokkaido oo1-oo21, Japan
}

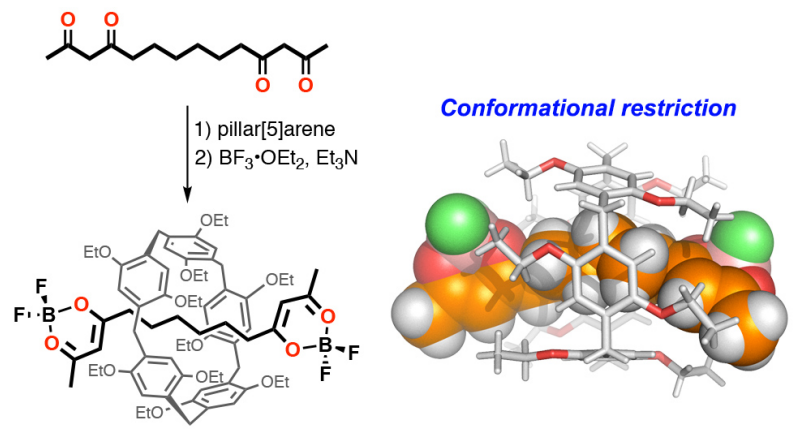

\begin{abstract}
Conformation control of aliphatic oligoketones bearing two 1,3-diketone subunits is achieved by molecular recognition with pillar[5] arene. Pillar[5]arene binds to aliphatic ketones, with association constants $K$ of $\sim 10^{1} \mathrm{M}^{-1}$, to form pseudo-rotaxanes. The pseudo-rotaxanes are locked by $\mathrm{BF}_{2}$-complexation at the 1,3-diketone sites through quasi-solid-state reactions. X-ray crystallography reveals linear conformations for the axis molecules. The effect of supramolecular conformational restriction is evaluated using an alkyl-linked dyad chromophore system that shows solvatochromism upon intramolecular aggregation.
\end{abstract}

Aliphatic polyketones are a class of indispensable precursors for the synthesis of natural products, pharmaceuticals, and functional materials. ${ }^{1}$ Structural diversity of polyketone-related products is derived from the conformational flexibility of aliphatic chains as well as the reactivities of multiple carbonyl groups. Polyketones with oligomethylene chains can adopt numerous conformations in solution. In biological systems, conformations of flexible substrates are sophisticatedly controlled by enzymes for efficient chemical transformations. ${ }^{2}$ Mimicking such systems, chemists have also developed various artificial hosts to control the conformations and orientations of structurally flexible substrates. ${ }^{3}$ However, substantial challenges still remain, especially for flexible substrates with many methylene units, because intermolecular interactions with simple hydrocarbons are usually not sufficiently strong to fix their conformations in solution.

Pillar[5]arene $\mathbf{1}$ is a macrocyclic host that can bind various aliphatic guests. ${ }^{4}$ Owing to the multiple $\mathrm{CH}-\pi$ interactions within the tight cavity, host 1 preferentially incorporates guest compounds with oligomethylene units to form (pseudo) rotaxanes. ${ }^{5}$ Such rotaxane formation is expected to restrict the conformations of guest molecules to be linear rather than curled or bent. Given the guest binding properties of pillar[5] arene $\mathbf{1}$, we examined the supramolecular conformational control of aliphatic oligoketones by rotaxane formation. In this work, we focused on aliphatic tetraketones $\mathbf{2 - 6}$ bearing various lengths of oligomethylene linkages between two 1,3-diketone subunits (Figure 1) as specific guests. As we have recently demonstrated with oligomers of acetylacetone derivatives, such 
aliphatic polyketones have the potential to be converted to aromatic chains, $\pi$-conjugated chromophores, ion-conducting materials, and multidentate imine ligands. ${ }^{6}$ Here, we show the inducement and fixation of linear conformations of aliphatic oligoketones through harnessing molecular recognition by pillar[5] arene 1. Although binding constants were rather small as compared with other hydrogen bonding guests, the induced conformations were locked by the non-pseudo rotaxane formation using $\mathrm{BF}_{2}-$ complexation at the 1,3-diketone units. Furthermore, the effects of supramolecular conformational restriction were evaluated by the suppression of intramolecular aggregation in an alkyl-bridged dyad chromophore system.

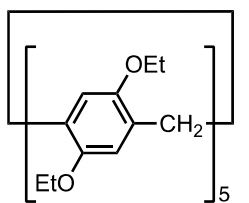

pillar[5]arene 1
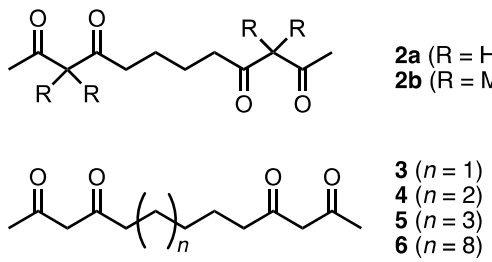

Figure 1. Structures of pillar[5]arene $\mathbf{1}$ and guest ketones 2-6.
Table 1. Association Constant $K$ for Pillar[5]arene and Tetraketone Guests ${ }^{a}$

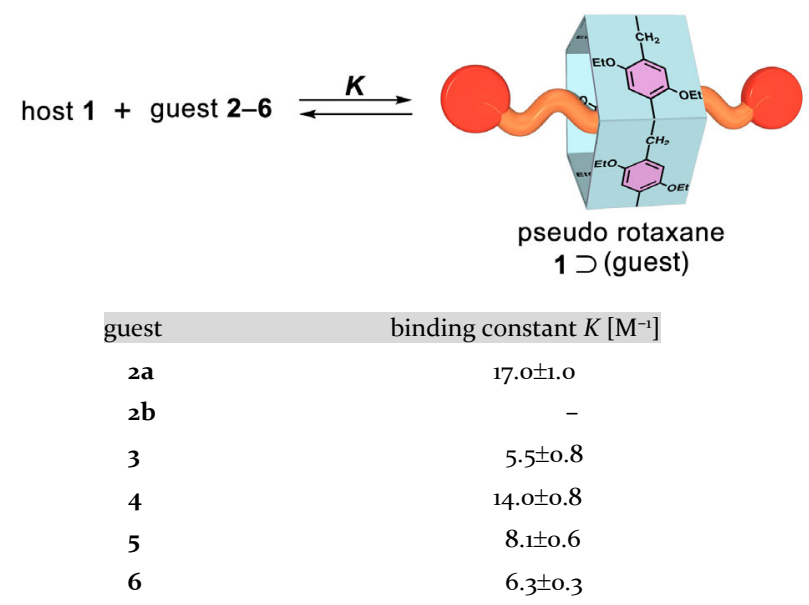

${ }^{a}$ Determined in $\mathrm{CDCl}_{3}$ by ${ }^{1} \mathrm{H}$ NMR titration.

Guest compounds 2-6 were prepared by reactions of the corresponding terminal dihaloalkanes and acetylacetone in an analogous manner to the reported procedure (see Supporting Information(SI)). ${ }^{7}$ In $\mathrm{CDCl}_{3}$ at a concentration of $10 \mathrm{mM}$, tetraketone $2 \mathbf{a}$ existed as an equilibrated mixture of enol/keto $=85: 15$ for the 1,3-diketone units. When one equivalent of host $\mathbf{1}$ was added to the solution, the methylene protons of $\mathbf{2 a}$ at the 6- and 7-positions upfield shifted from $1.65 \mathrm{ppm}$ to $1.34 \mathrm{ppm}$ in the ${ }^{1} \mathrm{H}$ NMR spectrum, which suggested a reversible formation of pseudo-rotaxane $\mathbf{1} \supset \mathbf{2 a}$. The Job's plot obtained by NMR titration clearly indicated the 1:1 complexation of $\mathbf{1}$ and $\mathbf{2 a}$ (Figure Sia). The association constant $K$ between $\mathbf{1}$ and $\mathbf{2 a}$ was determined to be $17.0 \pm 1.0 \mathrm{M}^{-1}$ using the non-linear curve-fitting theorem. ${ }^{8}$ It should be noted that tetramethyl-substituted analogue $\mathbf{2 b}$ showed no shift of signals in the ${ }^{1} \mathrm{H}$ NMR spectrum upon mixing with host 1, which implied that the doubly methylated acetylacetone subunit was too bulky to pass through the cavity of $\mathbf{1}$ (see SI).

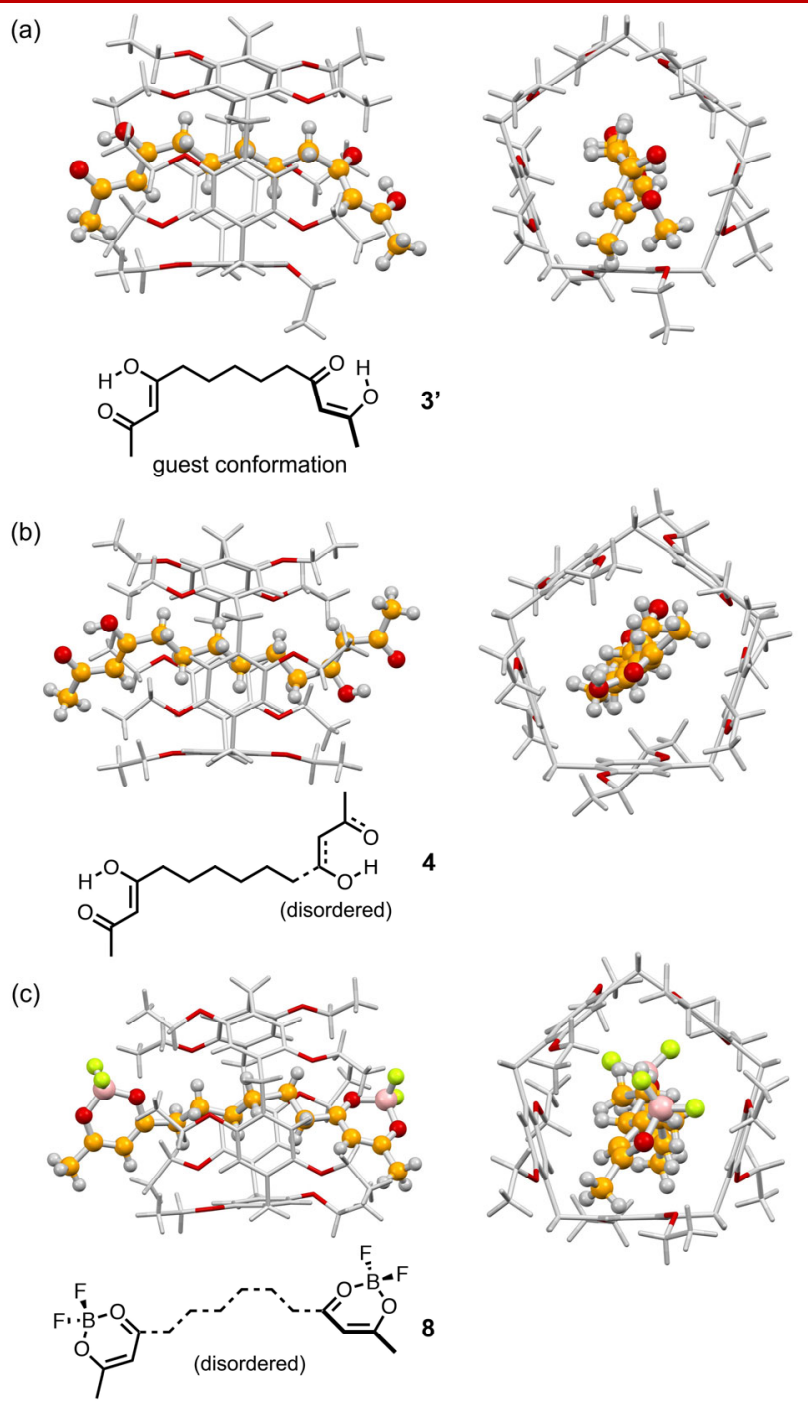

Figure 2. X-ray crystal structures of pseudo-rotaxanes (a) $1 \supset 3$ and (b) $\mathbf{1} \supset \mathbf{4}$, and locked rotaxane $\mathbf{1} \supset \mathbf{8}$ (left: top view, right: side view). Host $\mathbf{1}$ and guests are drawn as line and ball-and-stick models, respectively. The major parts are shown for disordered guests.

An odd-even effect for the number of bridging methylene units was observed in the association constants of tetraketones 2-6 (Table 1). While the association constant of $\mathbf{2 a}$ was approximately three times larger than that of pentamethylene-bridged 3, hexamethylene-bridged 4 exhibited a similar binding constant to that of $\mathbf{2 a}$. The oddeven effect became trivial as the chain length increased. Eventually, the longer analogue 6 with 12 methylene units showed $K=6.3 \pm 0.3 \mathrm{M}^{-1}$, which was comparable to that of the odd-number analogues. Although the association constants of tetraketones were on the order of $10^{1} \mathrm{M}^{-1}$, these 
values guaranteed almost 90\% complexation at a concentration of 1.o $\mathrm{M}$ for each component in chloroform.

The formation of pseudo-rotaxanes between host 1 and tetraketones 3 and 4 was unambiguously confirmed by single crystal X-ray diffraction analysis (Figure 2). When methanol was slowly diffused into a chloroform solution of 1 and 3 (molar ratio 1:3), colorless single crystals of pseudorotaxane $\mathbf{1} \supset \mathbf{3}$ were formed. In the crystal structure, guest $\mathbf{3}$ penetrated into the cavity of pillar[5]arene 1. Host 1 adopted a pseudo $C_{5}$-symmetric conformation in which all the aromatic rings adopted the same planar chirality. The two 1,3-diketone units in guest 3 were observed in the planar enol forms with an apparent bond length alternation (see SI).

As axis molecule 3 did not show disorder in the crystal structure, the observed tautomer of 3 was determined as $(3 Z, 11 Z)-4,12$-dihydroxytrideca-3,11-diene-2,10-dione (hereafter denoted as $\left.3^{\prime}\right)$. Weak hydrogen bonds between oxygen atoms of 3 ' and ethoxy groups of 1 were also proposed, owing to the short O-C distances ( 2.641 and $2.668 \AA$ ). The internal pentamethylene bridge of 3 ' adopted an all $s$-trans conformation. As reported for analogous rotaxane systems, ${ }^{9} \mathrm{CH}-\pi$ interactions were suggested by the distances of 2.999-3.431 $\AA$ between the guest methylene carbon and aromatic plane of $\mathbf{1}$. The torsion angles of $\mathrm{C}_{3}-\mathrm{C}_{4}-\mathrm{C}_{5}-\mathrm{C} 6$ and $\mathrm{C} 8-\mathrm{C}_{9}-\mathrm{C}_{10}-\mathrm{C}_{11}$ were $5.4^{\circ}$ and $84.4^{\circ}$, respectively, which rendered guest $3^{\prime}$ in a non-planar, twisted conformation.

While one 1,3-diketone unit of 4 was disordered because of keto-enol tautomerism, the other clearly showed a planar enol structure with bond length alternation. As seen in the crystal structure of $\mathbf{1} \supset \mathbf{3}$, the internal hexamethylene bridge adopted an all $s$-trans conformation so as to induce multiple $\mathrm{CH}-\pi$ interactions. The torsion angle of $\mathrm{C}_{3}-\mathrm{C}_{4}-\mathrm{C}_{5}-\mathrm{C} 6$ (non-disordered part) was $0.1^{\circ}$, which resulted in a roughly planar conformation of 4 . Because there was no significant difference in the host conformations between $\mathbf{1} \supset \mathbf{3}$ and $\mathbf{1} \supset \mathbf{4}$, the difference in the association constant $K$ was attributed to the conformational stability of the incorporated guests ketones inside the cavity of $\mathbf{1}$.

To fix the conformation of tetraketones induced by pil$\operatorname{lar}[5]$ arene $\mathbf{1}$, we examined the introduction of $\mathrm{BF}_{2}$-units at the 1,3-diketone sites of the axis molecule 4 as stoppers for rotaxane. We first synthesized the mono- $\mathrm{BF}_{2}-$ complex 7 by treatment of 4 with $\mathrm{BF}_{3} \cdot \mathrm{OEt}_{2}$ and triethylamine. The association constant of 7 to host 1 was determined to be $K=61$ $\pm 2.0 \mathrm{M}^{-1}$, which was $c a$. five times larger than that of 4 . Thus, we examined the direct synthesis of $\mathbf{1} \supset \mathbf{8}$ by the reaction between 4 and $\mathrm{BF}_{3} \cdot \mathrm{OEt}_{2}$ in the presence of host $1 .{ }^{1} \mathrm{H}$ NMR analysis of the reaction solution indicated a new set of highly up-field shifted peaks assignable to 'locked' rotaxane $\mathbf{1} \supset \mathbf{8}$ (see SI). Owing to the ring current effects of aromatic rings in $\mathbf{1}$, the methylene protons at the 6- and 7-positions of 8 were observed at -0.102 and -2.35 ppm, respectively, in $\mathrm{CDCl}_{3}$. However, rotaxane $\mathbf{1} \supset \mathbf{8}$ was isolated in only $10 \%$ yield after chromatographic separation. We thus conducted a quasi-solid-state reaction ${ }^{9}$ using crystals of $\mathbf{1} \supset \mathbf{4}$. When crystals of $\mathbf{1} \supset \mathbf{4}$ were ground with 30 equivalents of $\mathrm{BF}_{3} \cdot \mathrm{OEt}_{2}$ and 10 equivalents of triethylamine in a mortar with a pestle, rotaxane $\mathbf{1} \supset \mathbf{8}$ was formed in a yield of $21 \%$. The axis molecule $\mathbf{8}$ in rotaxane $\mathbf{1} \supset \mathbf{8}$ did not dissociate even in a refluxing toluene solution, which indicated that the $\mathrm{BF}_{2}$-unit had enough stability and bulkiness to maintain the interlocked structure.

\section{Scheme 1. Synthesis of rotaxane $1 \supset 8$}
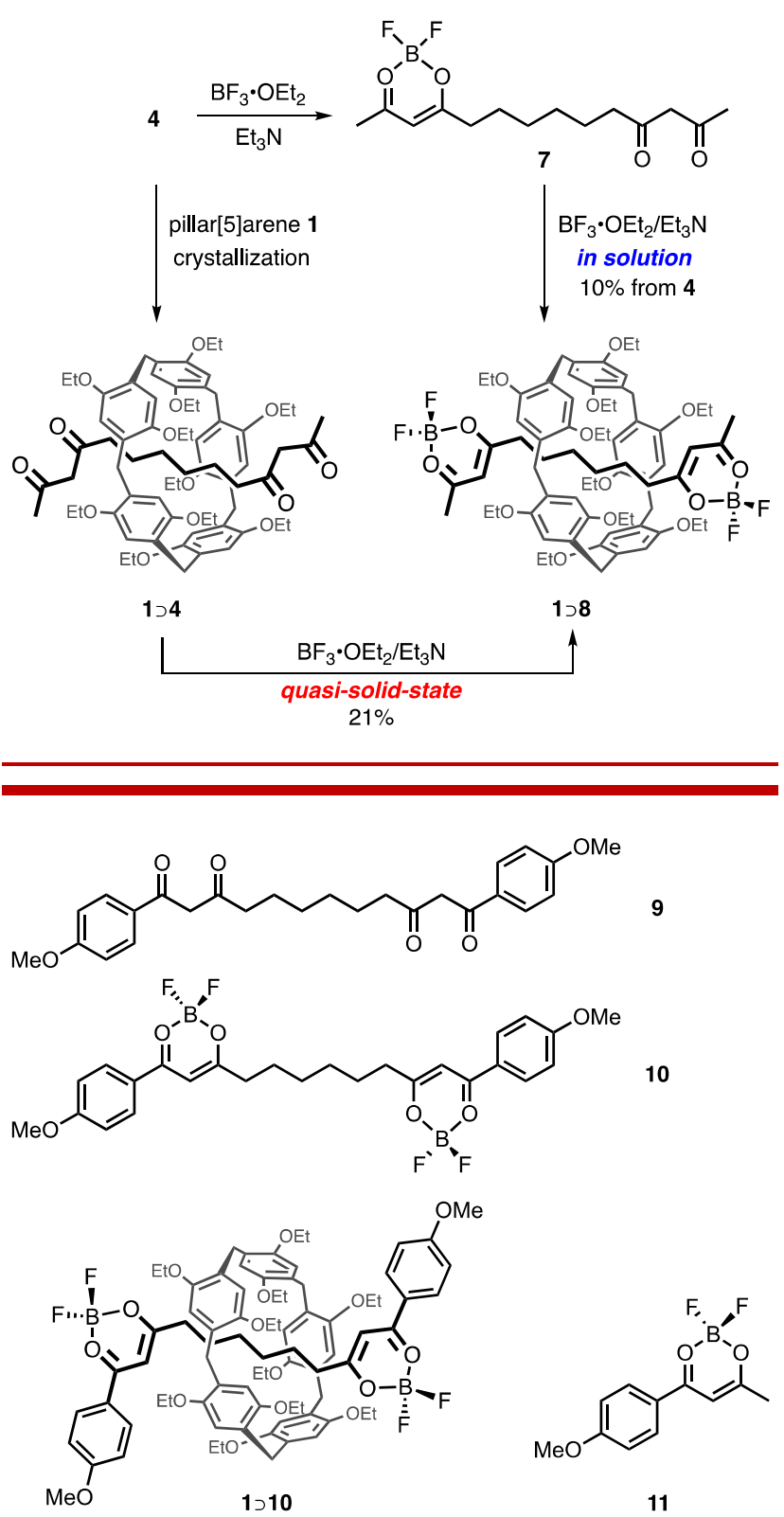

Figure 3. Structures of axis molecule 9, dyad chromophore 1o, rotaxane $\mathbf{1} \supset \mathbf{1 0}$, and monomer $\mathbf{1 1}$.

Single crystal X-ray analysis of $\mathbf{1} \supset \mathbf{8}$ revealed that the almost linear conformation of the axis molecule induced by pillar[5]arene $\mathbf{1}$ was still preserved after $\mathrm{BF}_{2}$-complexation (Figure 2c). While the hexamethylene bridges displayed positional disorder, the linear conformation of 8 rendered two boron atoms located at a distance of 12.4 $\AA$. These observations guarantee that supramolecular control by 
rotaxane formation can restrict the conformations of structurally flexible axis molecules so that both ends cannot contact each other even in solution.

To evaluate the effect of the supramolecular conformational restriction, we synthesized an alkyl-bridged dyad chromophore 10 as an axis molecule by $\mathrm{BF}_{2}$-complexation of 4-methoxyphenyl-substituted tetraketone 9. The dyad 10 exhibited a sharp absorption band at $362 \mathrm{~nm}$ in dichloromethane that was almost identical to that of monomer 11 (Figure 4(a) and SI). The absorption band was broadened in tetrahydrofuran (THF), and a new peak appeared at $349 \mathrm{~nm}$ in 1,4-dioxane. These spectral changes occurred almost independently with concentrations of chromophore 10 in the measurement range of UV-Vis absorption spectra $\left(10^{-9} \sim 10^{-6} \mathrm{M}\right)$. The solvatochromic behavior of 10 was attributed to the formation of an intramolecular aggregate ${ }^{10}$ in which the hexamethylene-bridge adopted a curved conformation. Therefore, the dyad system can be used as a probe for the conformational control of flexible oligomethylene bridges in solution.

(a)
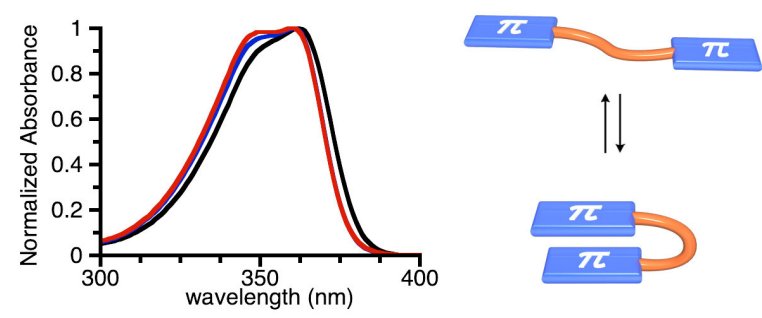

(b)

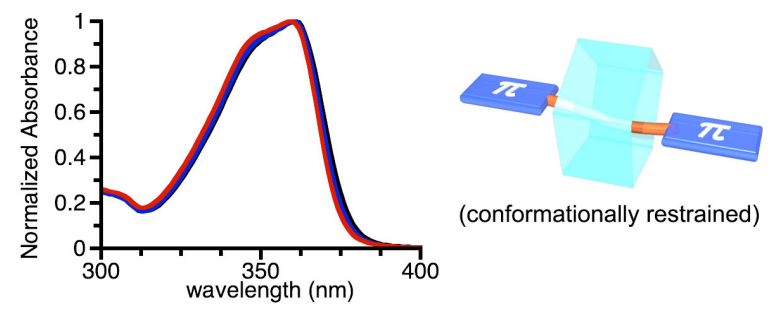

Figure 4. UV-vis absorption spectra of (a) axis molecule 10 and (b) rotaxane $1 \supset 10$ in $\mathrm{CH}_{2} \mathrm{Cl}_{2}$ (black), THF (blue), and 1,4-dioxane (red).

Rotaxane $\mathbf{1} \supset \mathbf{1 0}$ was synthesized by a quasi-solid-state reaction with a yield of $32 \%$ in a similar fashion to $1 \supset \mathbf{8}$. Single crystal X-ray analysis revealed that the five $\mathrm{H}_{2} \mathrm{C}-\mathrm{CH}_{2}$ bonds in the hexamethylene bridge of 10 adopted (from end-to-end) antiperiplanar, gauche, antiperiplanar, gauche, and antiperiplanar conformations in an almost similar fashion to $\mathbf{1} \supset \mathbf{8}$ (Figure 5). As a result, the axis molecule 10 adopted a rather linear conformation, which rendered the two boron centers to be well-separated with a distance of $12.5 \AA$.

Unlike pure compound 10, rotaxane $1 \supset \mathbf{1 0}$ showed virtually no solvatochromism. The absorption spectral shape of $1 \supset 10$ did not change in various solvents including dichloromethane, THF, and 1,4-dioxane (Figure 4(b)). In every solvent, the spectral shapes were almost identical to that of monomer 11 (SI). ${ }^{11}$ These results indicated that intramolecular aggregation of $\mathbf{1 0}$ was totally suppressed by supramolecular conformational control by rotaxane formation.

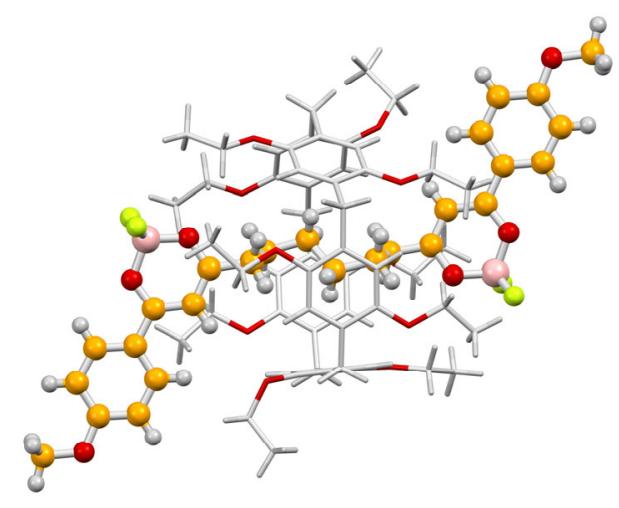

Figure 5. Crystal structure of rotaxane $\mathbf{1} \supset \mathbf{1 0 .}$

In conclusion, conformations of structurally flexible aliphatic oligoketones were controlled to be linear by inclusion into the cavity of pillar[5] arene. Despite the rather low association constants, pseudo-rotaxanes were efficiently locked by $\mathrm{BF}_{2}$-complexation at the 1,3-diketone subunits through quasi-solid-state reactions. The supramolecular conformational restriction was confirmed by solvatochromism of chromophore 10 in solution. Such a supramolecular approach will contribute to the efficient chemical conversion of aliphatic oligo- and polyketones in a conformationally-controlled fashion. In this sense, pillar[5]arenes can also be used as a molecular reactor for the conversion of aliphatic ketones into organic chromophores and other functional molecules.

\section{ASSOCIATED CONTENT}

\section{Supporting Information}

The Supporting Information is available free of charge on the ACS Publications website.

Experimental procedures and spectral data for all new compounds (PDF)

Single crystal X-ray diffraction data (CIF)

\section{AUTHOR INFORMATION}

\section{Corresponding Author}

Yasuhide Inokuma - Division of Applied Chemistry, Faculty of Engineering, Hokkaido University, Kita 13, Nishi 8, Kita-ku, Sapporo, Hokkaido o6o-8628, Japan; Institute for Chemical Reaction Design and Discovery (WPI-ICReDD), Hokkaido University, Kita 21, Nishi 1o, Kita-ku, Sapporo, Hokkaido oo1oo21, Japan; orcid.org/oooo-ooo1-6558-3356;

E-mail: inokuma@eng.hokudai.ac.jp 
Tomoki Ogoshi - Department of Synthetic Chemistry and Biological Chemistry, Graduate School of Engineering, Kyoto University, Katsura, Nishikyo-ku, Kyoto 615-8510, Japan; JST, CREST, 4-1-8 Honcho, Kawaguchi, Saitama 332-oo12, Japan; WPI Nano Life Science Institute, Kanazawa University, Kakuma-machi, Kanazawa 920-1192, Japan; orcid.org/ooooooo2-4464-0347;

E-mail: ogoshi@sbchem.kyoto-u.ac.jp

\section{ACKNOWLEDGMENT}

This work was supported by Grant-in-Aid for Young Scientists (A) (No. ${ }_{17} \mathrm{Ho}_{4872}$ ) and by the Asahi Glass Foundation, of which Y.I. is the principal investigator. Nano Life Science Institute (NanoLSI) and Institute for Chemical Reaction Design and Discovery (ICReDD) was established by World Premier International Research Initiative (WPI), MEXT, Japan.

\section{REFERENCES}

(1) (a) Robinson, R. The Structural Relations of Natural Products., Clarendon: Oxford, 1955; pp 4-10. (b) A. Das, C. Khosla, Acc. Chem. Res. 2009, 5, 631-639. (c) Money, T. Biogenetic-type Synthesis of Phenolic Compounds, Chem. Rev. 1970, 7o, 553-56o. (d) Hertweck, C. The biosynthetic logic of polyketide diversity. Angew. Chem. Int. Ed. 2009, 48, 4688-4716. (e) Fäseke, V. C.; Raps R. C.; Sparr C. Polyketide Cyclizations for the Synthesis of Polyaromatics Angew. Chem. Int. Ed. in press (DOI: 10.1002/anie.201911255).

(2) (a) Gilbreath, S. G.; Harris, C. M.; Harris, T. M. Biomimetic synthesis of pretetramides. 1. Synthesis of pretetramide by tandem extension of a polyketide chain. J. Am. Chem. Soc. 1988, 110, 61726179. (b) Hammerer, L.; Friess, M.; Cerne, J.; Fuchs, M.; Steinkellner, G.; Gruber, K.; Vanhessche, K.; Plocek, T.; Winkler, K. C.; Kroutil, W. Controlling the Regioselectivity of Fatty Acid Hydroxylation ( $\left.\mathrm{C}_{10}\right)$ at $\alpha$ - and $\beta$ - Position by $\mathrm{CYP}_{152} \mathrm{Al}_{1}\left(\mathrm{P}_{450 \mathrm{O} s} \beta\right)$ Variants. ChemCatChem. 2019, 11, 5642-5649. (c) Rentmeister, A.; Arnold, F. H.; Fasam R. Chemo-enzymatic fluorination of unactivated organic compounds Nat. Chem. Biol. 2009, 5, 26-28.

(3) (a) Trembleau, L.; Rebek, J., Jr. Helical Conformation of Alkanes in a Hydrophobic Cavitand. Science 2003, 301, 1219-1220. (b) Scarso, A.; Trembleau, L.; Rebek, J. Jr. Encapsulation Induces Helical Folding of Alkanes. Angew. Chem. Int. Ed. 2003, 42, 5499-5502. (c) Yu, Y.; Rebek J. Jr. Reactions of Folded Molecules in Water. Acc. Chem. Res. 2018, 51, 3031-3040. (d) Pavlović, R. Z.; Border, S. E.; Finnegan, T. J.; Zhiquan, L.; Gunther, M. J.; Munoz, E.; Moore, C. E.; Hadad, C. M.; Badjić, J. D. Twist-Turn-Twist Motif Chaperoned Inside Molecular Baskets. J. Am. Chem. Soc. 2019, 141, 16600 -16604. (e) Yamashita, M.; Kusaba, S.; Akita, M.; Kikuchi, T.; Yoshizawa M. Cramming versus threading of long amphiphilic oligomers into a polyaromatic capsule. Nat. Commun. 2018, 9, 4227. (4) (a) Ogoshi, T.; Kanai, S.; Fujinami, S.; Yamagishi, T.; Nakamoto, Y. para-Bridged Symmetrical Pillar[5]arenes: Their Lewis Acid Catalyzed Synthesis and Host-Guest Property. J. Am. Chem. Soc., 2008, 130, 5022-5023. (b) Cragg, P. J.; Sharma, K. Pillar[5]arenes: fascinating cyclophanes with a bright future Chem. Soc. Rev. 2012, 41, 597-607. (c) Leigh, D. A.; Marcos, V.; Wilson, M. R. Rotaxane Catalysts. ACS Catalyst. 2014, 4, 4490. (d) Ogoshi, T., Yamagishi, T.-a.; Nakamoto Y. Pillar-Shaped Macrocyclic Hosts Pillar[n]arenes: New Key Players for Supramolecular Chemistry. Chem. Rev. 2016, 116, 7937-8002. (e) Lou, X.; Chen, H.; Jia, X.; Li, C. Complexation of Linear Aliphatic Ester, Aldehyde and Ketone Guests by Per-ethylated Pillar[5]arene. Chin. J. Chem. 2015, 33, 335-338.

(5) (a) Wang, Y.; Ping, G.; Li, C. Efficient complexiation between pillar[5]arenes and neutral guests: from host-guest chemistry to functional materials. Chem. Commun., 2o16, 52, 9858-9872. (b) Strutt, N. L.; Forgan, R. S.; Spruell, J. M.; Botros, Y. Y.; Stoddart, J. F. Monofunctionalized Pillar[5]arene as a Host for Alkanediamines. J. Am. Chem. Soc., 2011, 133, 5668-5671. (c) Dong, S.; Han, C.; Zheng, B.; Zhang, M.; Huang, F. Preparation of Two New [2] Rotaxanes Based on the Pillar[5]arene/Alkane Recognition Motif. Tetrahedron Lett. 2012, 53, 3668-3671. (d) Wei, P.; Yan, X.; Li, J.; Ma, Y.; Yao, Y.; Huang, F. Novel [2]Rotaxanes Based on the Recognition of Pillar[5]arenes to an Alkane Functionalized with Triazole Moieties. Tetrahedron 2012, 68, 9179-9185.

(6) (a) Uesaka, M.; Saito, Y.; Yoshioka, S.; Domoto, Y.; Fujita, M.; Inokuma, Y. Oligoacetylacetones as shapable carbon chains and their transformation to oligoimines for construction of metal-organic architectures. Commun. Chem. 2018, 1, 23. (b) Manabe, Y.; Uesaka, M.; Yoneda, T.; Inokuma, Y. Two-Step Transformation of Aliphatic Polyketones into $\pi$-Conjugated Polyimines. J. Org. Chem. 2019, 84, 9957-9964. (c) Ashida Y.; Manabe. Y.; Yoshioka, S.; Yoneda, T.; Inokuma, Y.; Dalton Trans. 2019, 48, 818-822. (d) Yoneda, T.; Kasai, C.; Manabe, Y.; Tsurui, M.; Kitagawa, Y.; Hasegawa, Y.; Sarkar, P.; Inokuma, Y. Luminescent Coordination Polymers Constructed from a Flexible, Tetradentate Diisopyrazole Ligand and Copper(I) Halides. Chem. Asian J. 2020, 15, 601-605. (e) Eriksson, T.; Mace, A.; Manabe, Y.; Yoshizawa-Fujita, M.; Inokuma, Y.; Brandell, D.; Mindemark, J. Polyketones as Host Materials for Solid Polymer Electrolytes. J. Electrochem. Soc. 2020, 167,070537 .

(7) (a) Hampto, K. G.; Christie J. J. Cuprous Chloride Catalyzed Alkylations of $\beta$-Diketones with Methylene Harides. J. Org. Chem., 1976, 41, 2772-2773. (b) Maurer, C.; Pittenauer, E.; Du, V. A.; Allmaierb G.; Schubert, U. Cyclic Bis( $\beta$-diketonate)- and Bis( $\beta$ ketoesterate)-Bridged Titanium and Zirconium Alkoxide Derivatives. Dalton Trans., 2012, 41, 2346-2353.

(8) (a) Thordarson, P.; Determining Association Constants from Titration Experiments in Supramolecular Chemistry. Chem. Soc. Rev., 2011, 40, 1305-1323. (b) Fielding, L. Determination of Association Constants $\left(K_{\mathrm{a}}\right)$ from Solution NMR Data. Tetrahedron, 20oo, 56, 6151-6170.

(9) Holler, M.; Stoerkler, T.; Louis, A.; Fischer, F.; Nierengarten, J.-F. Mechanochemical Solvent-Free Conditions for the Synthesis of Pillar[5]arene-Containing [2]Rotaxanes. Eur. J. Org. Chem., 2019, 3401-3405.

(10) (a) Liang, K.; Farahat, M. S.; Perlstein, J.; Law, K.-Y.; Whitten D. G. Exciton Interactions in Nonconjugated Squaraine Dimers. Mechanisms for Coupling and Consequences for Photophysics and Photochemistry. J. Am. Chem. Soc. 1997, 119, 830-831. (b) Lu, L.; Lachicotte, R. J.; Penner, T. L.; Perlstein, J.; Whitten D. G. Exciton and Charge-Transfer Interactions in Noncojugated Merocyanine Dye Dimers: Novel Solvatochromic Behavior for Tethered Bichromophores and Excimers. J. Am. Chem. Soc. 1999, 121, 81468156. (c) Uranga-Barandiaran, O.; Catherin, M.; Zaborova, E.; D’Aléo, A.; Fages, F.; Castet, F.; Casanova, D. Optical properties of quadrupolar and bi-quadrupolar dyes: intra and inter chromophoric interactions. Phys. Chem. Chem. Phys. 2018, 20, 2462324632.

(11) Although axis molecule 10 emitted visible fluorescence, the emission was quenched in rotaxane $1 \supset 10$ presumably due to intramolecular electron transfer from pillar[5] arene to 1o. (a) Xu, S.; Evans, R. E.; Liu, T.; Zhang, G.; Demas, J. N.; Trindle, C. O.; Fraser, C. L. Aromatic Difluoroboron $\beta$-Diketonate Complexes: Effects of $\pi$-Conjugation and Media on Optical Properties. Inorg. Chem. 2013, 52, 3597-3610. (b) Q. Yao, B. Lü, C. Ji, Y. Cai and M. Yin, ACS Appl. Mater. Interfaces. 2017, 9, 36320-36326. (c) N. Hua, L. Shao, Z. Zhang, J. Sun, J. Yang, Sensors and Acturators B, 2018, 255, 14301435. (d) Q. Lin, L. Liu, F. Zheng, P-P. Mao, J. Liu, Y.-M. Zhang, H. Yao, T.-B. Wei. Tetrahedron, 2017, 73, 5307-5310. 